\title{
Studies on the Thiol Components of Isolated Nuclei
}

\author{
Michael Gronow \\ Cambridge Cancer Research Fund Laboratory 7 The Maltings, Cottenham, Cambridge, England, UK \\ Email: cam.cancer@btconnect.com,michael@gronow-cambridge.co.uk
}

How to cite this paper: Gronow, M. (2020) Studies on the Thiol Components of Isolated Nuclei. Journal of Analytical Sciences, Methods and Instrumentation, 10, 36-42. https://doi.org/10.4236/jasmi.2020.101003

Received: February 27, 2020

Accepted: March 23, 2020

Published: March 26, 2020

Copyright ( 2020 by author(s) and Scientific Research Publishing Inc. This work is licensed under the Creative Commons Attribution International License (CC BY 4.0).

http://creativecommons.org/licenses/by/4.0/

\begin{abstract}
The thiol components of the nonhistone proteins prepared from isolated nuclei from rat liver, regenerating liver and hepatoma 223 cells have been investigated after reaction with radio labelled $\mathrm{N}$-ethylmaleimide and 5-5'-dithiobis-(2-nitrobenzoic acid) (DTNB). The labelled adducts formed were examined by isoelectric focusing analysis in polyacrylamide gel and the distribution of the radiolabels within sliced portions of the gels determined. In the case of the ${ }^{14} \mathrm{C}$ labelled NEM adduct the label was found to be spread amongst numerous protein components within the gel however, in the case of the ${ }^{35}$ S labelled DTNB adducts, only a small proportion of the label was found in the protein material which was retained in the acidic isoelectric point (pI) region of the gel. The bulk of the ${ }^{35}$ S labelled adduct $(56 \%-60 \%)$ was found to have migrated into the anode solution (10 $\mathrm{mM}$ phosphoric acid). This could be adsorbed onto a hydrophobic resin (XAD2) resin and eluted with methanol. Gel filtration chromatographic analysis of this adduct material on BioGel P2, (exclusion limit 1500 daltons) showed low molecular weight components to be present. Slightly different patterns were obtained for these nuclei, each containing several ${ }^{35} \mathrm{~S}$ components with molecular weights greater than the Ellman reagent itself. These ${ }^{35}$ S labelled thiol components did not contain any protein, peptide or amino acid components indicating strongly that a novel species of thiols could be present in these nuclei bound within the non-histone protein matrices.
\end{abstract}

\section{Keywords}

Thiols, Isolated Cell Nuclei, Radiolabelled Thiol Adducts, Isoelectric Focusing Analysis

\section{Introduction}

Thiol compounds play vital roles in general cell metabolism and in the main- 
tenance of thiol-redox homeostasis, controlling cellular redox levels and combating oxidative stress. However, it has been known for nearly a century that they also have an important role in the control of cell division as demonstrated by the inhibition of division after the blocking of the cellular thiol groups with reagents such as mercuric chloride in synchronized dividing echinoderm eggs (sea urchin) [1], in amphibian eggs [2] and other species [3]. This blocking could have been, in part, due to the inhibition of respiration but could also be due to interference in the formation of the mitotic spindle via the thiol groups present in nuclear protein/chromatin mass.

Since then much published work has appeared on the role of thiols in cancer cell metabolism. This has clearly established that cellular thiols also play vital roles in radio sensitization and chemotherapeutic resistance of cancer cells. During the author's early cancer research work it was noted that, in cancer cells being studied, unidentified thiols were present, knowledge of which might be of use to improve the treatment of cancer. In view of the earlier thiol work it seemed logical to assume that those thiols intimately involved with the genetic material would be important, particularly with regard to radiation therapy. In seeking to find and identify these important cellular constituents, studies were carried out on the thiols present in the nuclei of normal and cancer cells.

During the initial work it was found that the bulk of the thiol containing components present in isolated nuclei could be extracted from the chromatin mass (DNA and histone) using the chaotropic agent, buffered $8 \mathrm{M}$ urea [4]. In order to obtain satisfactory analyses of these proteins, it was necessary to block the thiol groups with a suitable reagent, such as N-ethylmaleimide (NEM), to prevent the possibility of the formation if disulphide artefacts. The analysis patterns of ${ }^{14} \mathrm{C}$ labelled NEM adducts on isoelectric focusing gels revealed that the label was widely spread out amongst the stained protein bands [5].

In further studies another thiol blocking agent ${ }^{35}$ S-DTNB (Ellman reagent [6]) was employed which it was hoped would improve the separation by lowering the pI's of the thiol containing proteins. However, analysis of these ${ }^{35} \mathrm{~S}$ labelled thiol adducts by isoelectric focusing in polyacrylamide gels gave some unexpected results which are reported here.

\section{Materials and Methods}

Only materials and chemicals of the highest AR quality were used.

$\left[2,3-{ }^{14} \mathrm{C}\right]-\mathrm{NEM}$ and ${ }^{35} \mathrm{~S}$-labelled sodium sulphide were obtained from Amersham (now GE Healthcare) SJ21.

1) Preparation and extraction of nuclei

Male Wistar SPF (Specific Pathogen Free) rats (250 - 350 grm) were used for the preparation of liver nuclei using a slightly modified method of Chaveau et al. [7] in which $10 \mathrm{mM} \mathrm{Mg}^{2+}$ was incorporated into the sucrose solutions.

Nuclei were prepared from the livers of partially hepatectomized rats 24 hours after removal of two-thirds of the liver. 
Rat Hepatoma 223 (a 4-dimethylaminobenzene-derived tumour) was maintained in an ascitic form in the intraperitoneal cavity of the rats, usually harvested about 7 days after the original transplant. Nuclei were prepared from cells by osmotic shock in hypotonic solution $\left(5 \mathrm{mM} \mathrm{Ca}^{2+}\right)$ followed by homogenization in a tight gap all-glass homogenizer. Clean nuclei were obtained after centrifugation at 40,000 $\mathrm{g}$ in $2.4 \mathrm{M}$ sucrose [4].

The nuclei were extracted with $8 \mathrm{M}$ urea $50 \mathrm{mM}$ phosphate $\mathrm{pH} 7.6$ at $10^{\circ} \mathrm{C}$ containing a twofold excess of the thiol blocking reagent and after 15 mins the mixture was centrifuged at $3000 \mathrm{rpm}$ to sediment the DNA-histone complex. The supernatant obtained was dialysed 2 - 3 times against 100 volumes on deionized $8 \mathrm{M}$ urea to remove excess of reagent, until no further change in the specific activity of the was observed (i.e. to constant specific activity).

Procedure removes $70 \%$ of the total nuclear protein and $80 \%$ of the thiol present in isolated nuclei.

2) Isoelectric focusing (IEF) in polyacrylamide gels

This was carried out as previously described [5] in 5\% polyacrylamide gels, $2 \%$ ampholine carrier ampholytes pH 3.5 - 10 (LKB Produkter AB Stockholm, Sweden) in the presence of $8 \mathrm{M}$ urea (deionized), the sample being incorporated directly into the gel mixture prior to polymerization. $10 \mathrm{mM} \mathrm{H}_{3} \mathrm{PO}_{4}$ was used for the anode solution and $20 \mathrm{mM} \mathrm{NaOH}$ at the cathode. In these runs focusing was continued longer than the usual 5 hours, for 24 hours (at $15^{\circ} \mathrm{C}$ ).

3) Chromatography of $X-S-{ }^{35} S-T N B$ released into anode solution

The anode solution $\left(10 \mathrm{mM} \mathrm{H}_{3} \mathrm{PO}_{4}\right)$ after isoelectric focusing of the nuclear 8 $M$ urea extracts of the nuclei were stirred for 1 hour at room temperature with Amberlite XAD2 resin. Three extractions each of $0.1 \mathrm{~g}$ XAD2 $/ \mathrm{ml}$ were sufficient to remove all the ${ }^{35} \mathrm{~S}$ material from solution. The beads were filtered off, washed with water and the labelled mixed disulphides removed with methanol. This was then evaporated to dryness in a rotary evaporator and the solid obtained dissolved in a 1:1 mixture of methanol and $10 \mathrm{mM}$ phosphate $\mathrm{pH}$ 7.6. The pale-yellow solution obtained was chromatographed on a $30 \times 2.5 \mathrm{cms}$ column of Bio-Gel P2 (BioRad) at room temperature and eluted with $50 \mathrm{mM}$ sodium phosphate $\mathrm{pH} 7.6 ; 5 \mathrm{ml}$ fractions were collected.

4) Radio-isotope measurements

Polyacrylamide slices were solubilized in hydrogen peroxide and counted in a Multimat 8 scintillation counter (Intertechnique Ltd., Portslade, Sussex, UK) after dissolving in either Bray's [8] or Triton X-100 scintillator cocktails; the dpm being computed from the data obtained from a set of quenched standards in these scintillation mixtures.

5) Protein and amino acid analysis

Protein contents were measured by the standard Folin Lowry method using bovine serum albumin as a standard.

Full cysteine and other amino acid assays were carried on an ion exchange auto analyser by the Protein \& Nucleic Acid chemistry facility of the Department 
of Biochemistry at the University of Cambridge.

\section{Results and Discussion}

From the specific activities of the ${ }^{35} \mathrm{~S}$ and ${ }^{14} \mathrm{C}$ labelled non-histone nuclear proteins it was calculated that that the liver NHP proteins contained 68 - 75 nanomoles of thiol per mg of protein and the Hepatoma NHP 70 - 80 nanomoles of thiol per mg of protein. Only about half of this thiol material can be detected in normal buffer extractions, the other half can only be measured in the presence of high concentrations of chaotropic agents such as urea and guanidinium hydrochloride [4] [9].

Isoelectric focusing on all the three types of nuclei gave essentially the same result examples of which are shown in Figure 1.

In the case of the ${ }^{14} \mathrm{C}$-NEM labeled proteins all of the radiolabel remained within the gel after IEF. No radio label was found in either electrode solution. Over $85 \%$ of the applied ${ }^{14} \mathrm{C}$ label was recovered in the gel slices.

However, in the case of the ${ }^{35} \mathrm{~S}$ labelled protein adducts only a small amount of the ${ }^{35} \mathrm{~S}$ incorporated into the gel mixture prior to IEF was found to be retained in the acidic portion of the gel. It was found that, after isoelectric focusing of these $M=8 \mathrm{M}$ urea extracts, $56 \%-65 \%$ of the ${ }^{35} \mathrm{~S}$ migrated to the anode solution (10 $\mathrm{mM}$ phosphoric acid). $10 \%-12 \%$ was retained in the gel slices and $0.3 \%-0.5 \%$ was found the cathode solution $(20 \mathrm{mM} \mathrm{NaOH}) .75 \%$ recovery of applied ${ }^{35} \mathrm{~S}$ dpm was achieved.

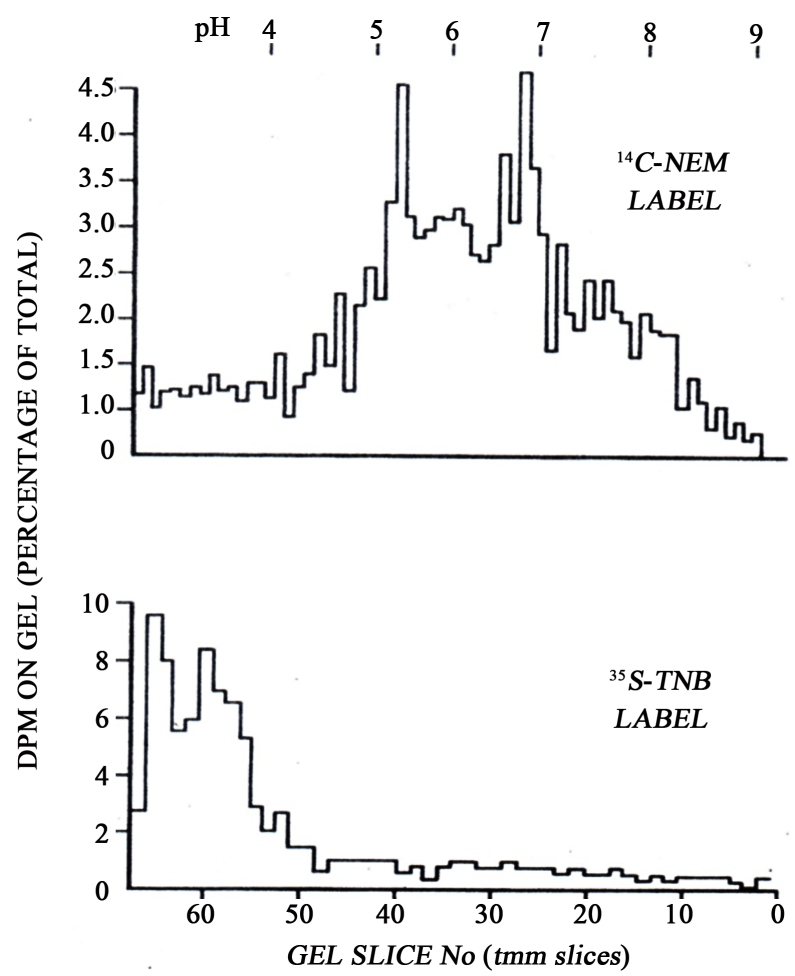

Figure 1. Isoelectric focusing in 5\% polyacrylamide gel of non-histone proteins extracted from rat liver nuclei with $8 \mathrm{M}$ urea $50 \mathrm{mM}$ phosphate. 
[Later investigations (unpublished) revealed that some of the low molecular weight ${ }^{14} \mathrm{C}$-NEM adducts could be released from the protein in the $8 \mathrm{M}$ urea extract by dialysis against a combination of EDTA and high salt concentrations.]

The ${ }^{35} \mathrm{~S}$ adduct material found in the anode after IEF was found to be dialysable but it could be adsorbed onto XAD2 resin. $100 \%$ of the ${ }^{35} \mathrm{~S}$ adsorbed could be recovered from the resin by methanol extraction. Gel filtration chromatography on BioGel P2 revealed the presence of adducts of molecular weight of less than 1500 (exclusion limit of this gel is 1500 daltons). Patterns obtained are shown in Figure 2.

Comparison of the elution times of the TNB adducts of glutathione (GSH), reduced $\alpha$-lipoic acid and DTNB itself indicated the unknowns to have molecular weights of 600 or more but less than 1500, as shown by the Blue Dextran or insulin markers which are excluded from the P2 gel. No GSH adducts were found in the anode solution.

The P2 patterns from the different nuclei look similar but the component peaks are definitely different; as would be expected from the diffent nuclei studied. Further analytical work is needed to establish the nature and importance of these low molecular weight thiols in the metabolism of cell nuclei.

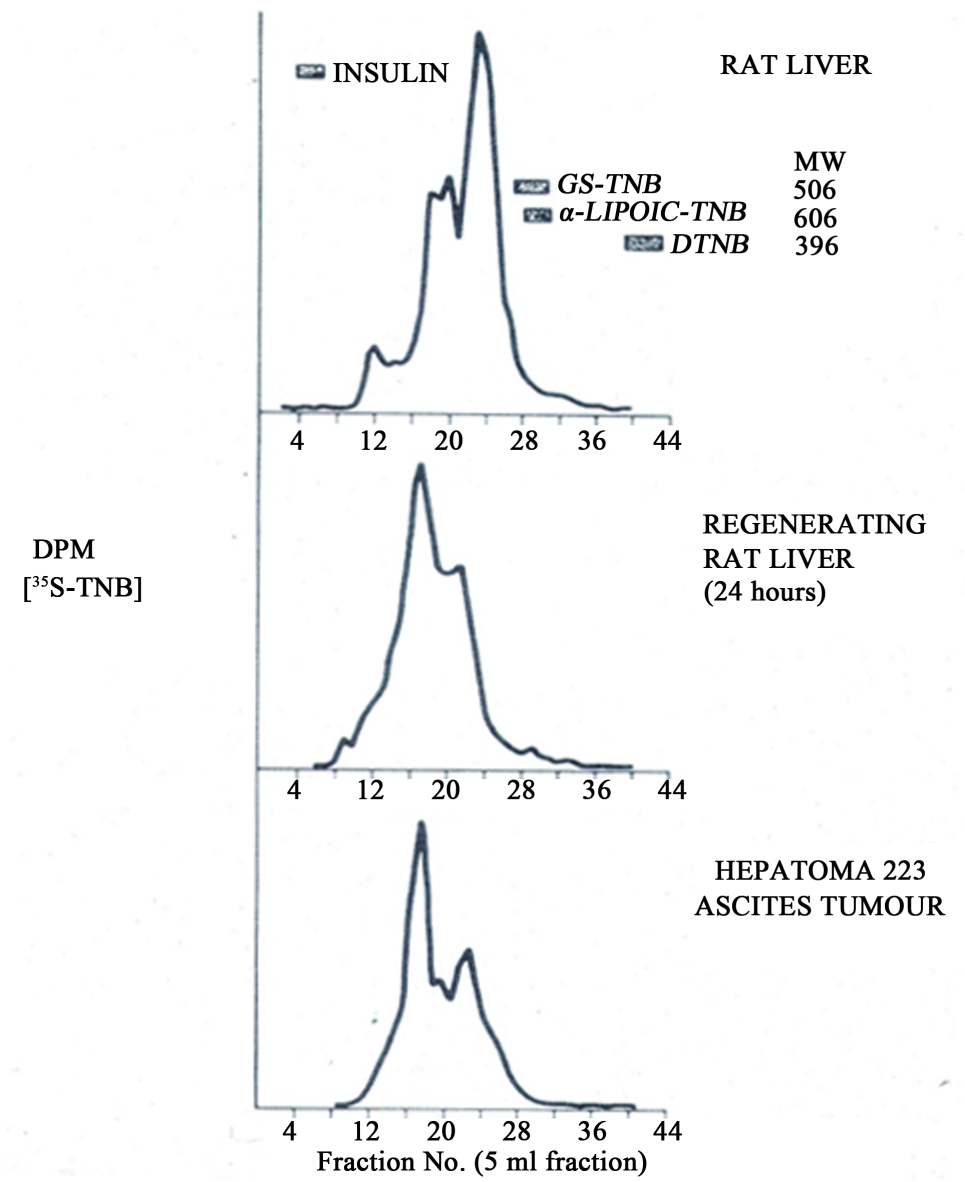

Figure 2. Gel filtration of ${ }^{35} \mathrm{~S}$ TNB adducts from anode solution on a $30 \times 2 \mathrm{cms}$ column of Bio-Gel P2 eluted with $50 \mathrm{mM}$ phosphate buffer $\mathrm{pH}$ 7.6. 


\section{Conclusions}

Of the thiols present in three types of nuclei studied, normal and regenerating liver and hepatoma tumour cells, only a small percentage are associated with the cysteine residues of the non-histone proteins. It has been shown that the bulk of the ${ }^{35} \mathrm{~S}$ labelled thiol adducts present in the NHP are unknown as non-protein low molecular species. Although normally buried or strongly attached to these proteins they can be detached during IEF in polyacrylamide gel. They could have important roles in the control of cell division control and/or gene transcriptional activity.

Knowledge of their composition and structure could aid the design of new, more effective, chemotherapeutic and radio sensitizing drugs for cancer treatment.

\section{Acknowledgements}

Some of this work was carried out earlier at the Chemistry Department at the University of York and later continued at the CCRF research laboratories in Cambridge. The author is grateful to the Yorkshire Cancer Campaign and Cambridge Cancer Research Fund for financial support during this work.

\section{Conflicts of Interest}

The author has no conflicts of interest (political, personal, religious, ideological, academic, intellectual, commercial or any other) to declare in relation to this manuscript.

\section{References}

[1] Rapkine, L. (1931) Sur les processus chimiques au cours de la division cellulaire. Ann. Physiol., 7, 382-417.

[2] Brachet, J. (1959) The Role of Sulfhydryl Groups in Morphogenesis. Journal of EXperimental Zoology, 142, 115-139. https://doi.org/10.1002/jez.1401420105

[3] Mazia, D. (1961) The Cell. In: Brachet, J. and Mirsky, A., Eds., Academic Press, New York, Vol. 3, 250.

[4] Gronow, M. (1969) Solublization and Partial Fractionation of the Sulphur-Containing Nuclear Proteins of Hepatoma 223 Ascites Cells. European Journal of Cancer, 5, 497-508. https://doi.org/10.1016/0014-2964(69)90104-2

[5] Gronow, M. and Thackrah, T. (1973) The Nonhistone Nuclear Proteins of Some Rat Tissues. Arch. Archives of Biochemistry and Biophysics, 158, 377-386. https://doi.org/10.1016/0003-9861(73)90634-6

[6] Ellman, G.L. (1959) Tissue Sulfhydryl Groups Arch. Archives of Biochemistry and Biophysics, 82, 70-77. https://doi.org/10.1016/0003-9861(59)90090-6

[7] Chaveau, J., Moule,Y. and Rouiller, C. (1956) Isolation of Pure and Unaltered Liver Nuclei Morphology and Biochemical Composition. Experimental Cell Research, 11, 317-321. https://doi.org/10.1016/0014-4827(56)90107-0

[8] Bray, G.A. (1960) A Simple Efficient Liquid Scintillator for Counting Aqueous Solutions in a Liquid Scintillation Counter. Analytical Biochemistry, 1, 279-285. 
https://doi.org/10.1016/0003-2697(60)90025-7

[9] Marsh, W.H., Ord, M.G. and Stocken, L.A. (1964) Thiol Proteins from Nuclei from Rat Liver and Thymus. Biochemical Journal, 91, 539.

https://doi.org/10.1042/bj0930539

\section{Abbreviations}

NEM: N-ethylmaleimide

DTNB: 5-5'-dithiobis-(2-nitrobenzoic acid)

GSH: Glutathione

TNB: 5-thio-2-nitro benzoic acid

IEF: Isoelectric Focusing

NHP: Non-Histone Protein

pI: Isoelectric Point

\section{Supplementary Information}

Synthesis of 35S-labelled Ellman's Reagent

This was prepared by Ellman's original method [5] using 35S-labelled sodium sulphide (Amersham (now GE Healthcare) SJ21) as shown below: -

PREPARATION OF $35 S-L A B E L L E D$ S, 5'DITHIOBIS-(2-NITRO-BENZOIC ACID)-DTNB
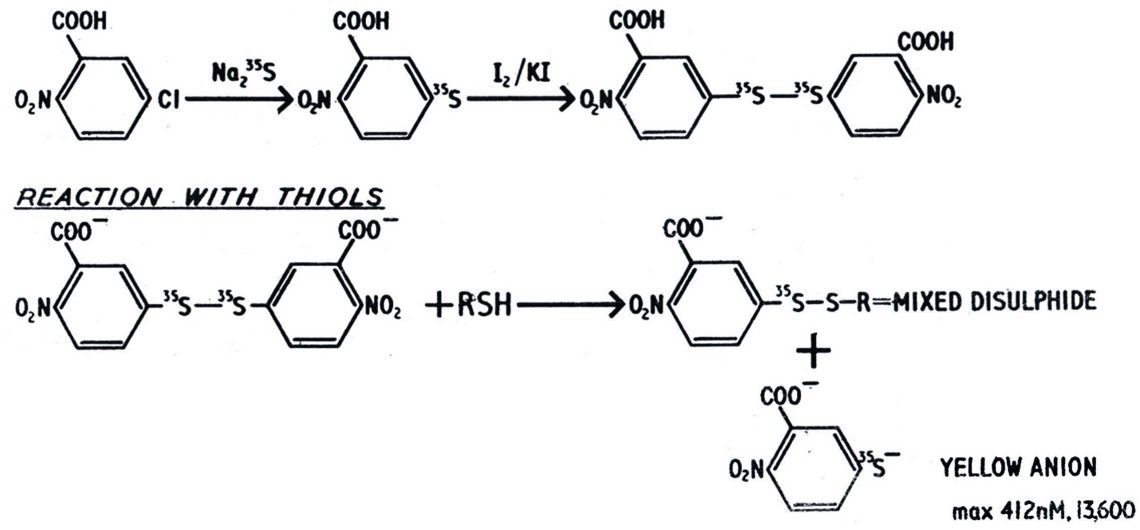

The labelled DTNB was recrystallized once from glacial acetic acid and shown to give essentially one spot/component on thin layer chromatography.

For labelling of nuclear thiol proteins material of specific activity of 17.5 $\mathrm{mCi} / \mathrm{mM}$ was usually employed. 